\title{
The Leverage of Growth Firms
}

\author{
Sheen Liu \\ Washington State University - Pullman
}

Theories on the capital structure of growth firms produce inconsistent and puzzling results. We revisit the Modigliani and Miller (M\&M) theory on capital structure and value of tax shields. Using the M\&M's arbitrage pricing arguments, we are able to extend the theory to growth firms and reconcile the theories of capital structure for growth firms with the M\&M theory for no-growth firms. We unify the theories and resolve the puzzles raised in the literature.

\section{INTRODUCTION}

What is the debt of a growth firm? The answer to the question seems to be a no-brainer: the debt is on the firm's balance sheet. This sounds obvious, but "never assume the obvious is true," says William

Safire $^{2}$. When we use a growth-firm's debt on balance sheet to value the value of tax shields (VTS) or the equity value of the firm, we find puzzling results.

Modigliani and Miller (M\&M, 1958, 1963) developed the classic capital structure theory for nogrowth firms. VTS as the gain from capital structure is one of the most significant results of corporate finance. Later theories of capital structure relaxed the M\&M's no-growth assumption in various ways and extended the theory to growth firms (Mayer (1973), Miles and Ezzell (1980), Harris and Pringle (1985), Ruback (2002), Fernández (2004), Cooper and Nyborg (2006)). Within those theories Fernández (2004) points out some puzzling results. One is that the VTS can be greater than the value of the debt itself. "This hardly makes any economic sense," Fernández (2004) comments. Moreover, "the (levered) equity is worth more than the unlevered equity" Fernández (2004). The results seem to defy the M\&M theory on VTS and the equity relation between growth and no-growth firms. Fernández proposes abandoning the M\&M approach in valuing VTS, which are the present value of future tax savings. On the contrary, Cooper and Nyborg (2006) insist on preserving the present value approach in determining VTS. Still, the puzzles pointed out by Fernández are not answered and the question as to whether the valuation of growth firms should be fundamentally different from the valuation of no-growth firms is not resolved. The question is interesting to the academic and also has practical importance.

The valuation of a growth firm is important for practitioners ( Brealey and Myers (2007), Brigham and Daves (2007), and Fernández (2007)). Capital structure and VTS are important factors in valuing levered growth-firms. Capital structure and VTS affect the weighted average cost of capital (WACC) of levered growth-firms. Furthermore, the beta of an unlevered firm is often inferred from the beta of a corresponding levered firm whose value depends on the VTS. In this sense, even the value of debt-free growth firms is affected by the value of the corresponding levered growth-firm.

Most firms are either growing or shrinking (growing negatively). Theories of growth-firm can be developed by relaxing the assumptions in the M\&M theory in various ways. However, even if we accept 
different theories can be expected, generalized theories should not contradict to the M\&M theory. Nogrowth firms are just special cases of growth firms. If the valuation of growth firms is not applicable to no-growth firms by setting growth rate to zero, one may question, like Fernández (2004) and Liu (2009), whether our valuation approach is fundamentally flawed. In addition, the debt, leverage, and VTS of growth firms are basic concepts in finance, accounting, and economics. Calling them textbook concepts is hardly an exaggeration.

We contribute to the literature by reexamining the debt, leverage, and VTS of growth firms. Starting with the valuation of no-growth firms and then relaxing the no-growth assumption, we extend the M\&M theory to growth firms. This exercise suggests that, if the future interest payment growth is taken into account in a firm's liability, not the liability on the firm's balance sheet, then the M\&M theory can be applied to a growth firm directly. We derive a set of unified formulas applicable to both growth and nogrowth firms.

The paper is organized as follows. The Debt of a Growth Firm revisits the M\&M theory, and extends it to growth firms. The Unified Formulas for the VTS summarizes the unified formulas that can be used for both growth and no-growth firms. The Puzzles and Answers searches the cause of the puzzlement for the theories of growth firms, and resolves the puzzles. The Discussions makes some final comments on the concept of implied debt that is introduced in this paper.

\section{DEBT OF A GROWTH FIRM}

The adjusted present value approach (APV, Modigliani and Miller (1958)) separates the value of operations into two components: the value of operations as if the company were unlevered and the VTS that arises from debt financing. A debt-free firm becomes a levered firm after restructuring. The levered firm is valued more than the unlevered firm by the additional VTS ${ }^{3}$. We summarize the APV approach for no-growth firm before we generalize it to growth firms.

Let us denote by a random variable $\tilde{X}$ the net operating income (NOI) generated by an all equity firm

in some state risk class, $k$. The NOI $\tilde{X}$ can be expressed in the form $X Z$, where $X$ is the expected value of $\tilde{X}$. The random variable $Z=\tilde{X} / X$ has the same distribution for all firms in class $k, Z$ is a drawing from the distribution. $F C F$ is defined as the free cash flows of a firm of size $X$ :

$$
F C F=(1-T) X+\delta-C-\Delta W
$$

where $\delta$ is depreciation, $C$ is capital expenditures and other operating investments (capital expenditures for short), $\Delta W$ is the change in working capital. For a no-growth firm, the depreciation each year must be replaced by capital expenditures in order to keep the same amount of capital in place and $\Delta W$ is zero. Thus

$$
F C F=(1-T) X \text { for } \delta=C \text { and } \Delta W=0
$$

Let $K_{U}$ be the rate at which the market capitalizes the expected NOI net of tax of an unlevered firm in class $k$. The value of an unlevered firm is a perpetuity:

$V_{U}=\sum_{i=1}^{\infty} \frac{(1-T) X}{\left(1+K_{U}\right)^{i}}=\frac{(1-T) X}{K_{U}}$

After restructuring a firm issues "a permanent level of debt" (?). Let $K_{D}$ be the cost of debt, the rate at which the market capitalizes the cash flow streams generated by debt. The value of a consol, a debt with an infinite maturity, is given by 


$$
D=\frac{I}{K_{D}}
$$

where $I$ is coupon payments. The value of a levered firm (after restructuring) is the sum of the value of the unlevered firm (before restructuring) and the tax savings from the debt:

$V_{L}=\frac{(1-T) X}{K_{U}}+T \frac{I}{K_{D}}=V_{U}+T D$

where $T$ is the corporate tax rate. Thus, the difference of the firm value before and after restructuring is the VTS, $T D^{4}$.

The cost of assets and the cost of equity of a levered firm can be related to the cost of unlevered firm and the cost of debt. The cost of the assets, $K_{L}$, is given by

$K_{L}=\frac{(1-T) X}{V_{L}}=K_{U}\left(1-T \frac{D}{V_{L}}\right)$

In the accounting identity the levered equity $S$ is defined as

$$
S=V_{L}-D
$$

The cost of levered equity, $K_{E}$, is give by

$K_{E}=\frac{(1-T)(X-I)}{S}=K_{U}+\frac{D}{S}(1-T)\left(K_{U}-K_{D}\right)$

Next, we extend the results to growth firms. For an unlevered growth firm its net operating profit after tax is given by

$N_{O P A T}=(1-T) X_{i}$

where subscript $i$ is time period. The free cash flow for an unlevered firm is

$F C F_{U, i}=N O P A T_{i}+\delta_{i}-C_{i}=(1-T) X_{i}+\delta_{i}-C_{i}-\Delta W_{i}$

The capital expenditures covers depreciation, working capital changes, and investment in the growth of NOI.

$C_{i}=G_{i}+\delta_{i}-\Delta W_{i}$

where $G_{i}$ is retained earnings invested in the growth of NOI. Substituting (7) into (6) we have

$$
F C F_{U, i}=(1-T) X_{i}-G_{i}
$$

Let $\eta$ be the plowback ratio, then $G_{i}$ can be rewritten as

$$
G_{i}=\eta(1-T) X_{i}
$$

The future $F C F$ s with a growth rate of $g$ are given by 


$$
\begin{aligned}
& F C F_{U, 0}=(1-\eta)(1-T) X_{0} \\
& F C F_{U, 1}=(1-\eta)(1-T) X_{1}=(1+g)(1-\eta)(1-T) X_{0} \\
& \ldots \\
& F C F_{U, i}=(1+g)^{i}(1-\eta)(1-T) X_{0}
\end{aligned}
$$

Applying growing perpetuity we have the value of an unlevered growth firm,

$V_{U, 0}=\sum_{i=1}^{\infty} \frac{F C F_{U, i}}{\left(1+K_{U}\right)^{i}}=\frac{(1-\eta)(1-T) X_{1}}{K_{D}-g}$

The assumption on the firm's debt is crucial to a theory of growth firms. The M\&M's assumption of "a permanent level of debt" can be extended to a growth firm. Such an extension implies a decreasing leverage ratio and an initially levered growth-firm eventually approaches an all equity firm. Some growth firms might follow the pattern of decreasing leverage, but most of growth firms do not.

A more realistic assumption is constant leverage ratio (?). Under this assumption, a firm's debt grows at the same rate as the firm's equity. To maintain a constant leverage, the firm issues each year additional debt so that the total debt increases at the same rate of the firm's NOI. The debt financing does not affect the firm's NOI, while the interest tax savings increase the firm's free cash flows:

$F C F_{L, i}=X_{i}-T\left(X_{i}-I_{i}\right)-G_{i}$

$=(1-T) X_{i}+T I_{i}-G_{i}$

The interest payments $I_{i}$ grow at the same rate of $g$, that is

$$
F C F_{L, t+i}=(1+g)^{i}\left[(1-\eta)(1-T) X_{t}+T I_{t}\right]
$$

The value of a levered firm is the sum of the value of the unlevered firm and the VTS

$V_{L, t}=\sum_{i=1}^{\infty} \frac{(1+g)^{i}(1-\eta)(1-T) X_{t}}{\left(1+K_{U}\right)^{i}}+\sum_{i=1}^{\infty} \frac{(1+g)^{i} T I_{t+i}}{\left(1+K_{D}\right)^{i}}$

and

$D_{t}^{*}=\sum_{i=1}^{\infty} \frac{I_{t}(1+g)^{i}}{\left(1+K_{D}\right)^{i}}=\frac{I_{t+1}}{K_{D}-g}$

It should be noted that $D_{t}^{*}$ is not the debt on the firm's balance sheet, but the debt implied by the future interest payments. Using $D_{t}^{*}$ the value of a levered growth firm is given by

$V_{L, t}=V_{U, t}+T D_{t}^{*}$

(13) has the same expression as the original M\&M relation, in which $V T S_{t}=T D_{t}^{*}$, except we replace $D$ in (2) with $D_{t}^{*}$. In M\&M $D$ is the present value of future interest payments and so is $D_{t}^{*}$. The difference is that $D$ is the debt on a firm's balance sheet but $D_{t}^{*}$ is not, $D$ in M\&M does not change with time while $D_{t}^{*}$ increases with time.

Let fix the time at $i=0$ and denote the debt on the current balance sheet by $D_{0}$. Then we have

$$
I_{1}=K_{D} D_{0} \text { or } D_{0}=\frac{I_{1}}{K_{D}}
$$

The debt on balance sheet and the debt implied by future growing interest payments have relation 
$D_{0}^{*}=\frac{K_{D}}{K_{D}-g} D_{0}$

With (14) we can rewrite (13) with $D_{0}$

$V_{L, t}=V_{U, t}+T \frac{K_{D}}{K_{D}-g} D_{0}$

If debt is based on a firm's balance sheet $D_{0}$, then we have a different formula (15) for levered firms.

We have two measures of debt of a levered firm, (15) is based on $D_{0}$ and (13) is based on $D_{0}^{*}$. In principle, which one we use is not an issue. They can be converted one another using (14). The issue lies with the consistency: if VTS is based on future growing interest payments, then the liability must be the present value of future growing interest payments. The inconsistencies are sources of puzzlement (see the Discussions).

Now it is straightforward to have other formulas and expressions using $D_{t}^{*}$. The return on assets $K_{L}$ is given by

$$
K_{L}=K_{U}-\frac{D_{t}^{*}}{T} T\left(K_{U}-K_{D}\right)
$$

and return on equity $K_{E}$ is give by

$$
K_{E}=K_{U}+\frac{D_{t}^{*}}{S_{t}}(1-T)\left(K_{U}-K_{D}\right)
$$

The above two equations are the same as (3) and (4) except $D$ is replaced by $D_{t}^{*}$.

Using implied debt $D_{t}^{*}$ we extend the M\&M to growth firms. Setting the growth rate to be zero in the formulas for growth firms we recover all relations for no-growth firms. In the following section, we introduce new notations so that the same set of relations is applicable to both growth and no-growth firms.

\section{UNIFIED FORMULAS FOR THE VTS}

We introduce a set of symbols that take in growth rate $g$

$$
K_{U}^{*}=K_{U}-g, \quad K_{D}^{*}=K_{D}-g, \quad K_{E}^{*}=K_{E}-g, \quad K_{L}^{*}=K_{L}-g
$$

Using the new symbols we have

$$
\begin{gathered}
D_{t}=\frac{I_{t+1}}{K_{E}^{*}}, S_{t}=\frac{(1-T)\left(X_{t+1}-I_{t+1}\right)}{K_{E}^{*}}, \\
V_{U, t}=\frac{(1-T) X_{t+1}}{K_{U}^{*}}, V_{L, t}=\frac{X_{t+1}}{K_{L}^{*}}
\end{gathered}
$$

which are the same as those for no-growth firms. Plus the formulas of $K_{E}^{*}, K_{U}^{*}$, and $K_{L}^{*}$ all formulas are the same for both growth and no-growth firms. The unified formulas are summarized in Table 1. 
TABLE 1

UNIFIED FORMULAS FOR GROWTH AND NO-GROWTH FIRMS

$$
K_{U}^{*}=K_{U}-g, K_{E, t}^{*}=K_{E, t}-g, K_{L, t}^{*}=K_{L, t}-g, K_{D}^{*}=K_{D}-g .
$$

\begin{tabular}{|l|l|}
\hline & Unified formula \\
\hline 1 & $V_{U}=\frac{(1-T) E\left(X_{t+1}\right)}{K_{U}^{*}}$ \\
\hline 2 & $V T S_{t}=T D_{t}^{*}$ \\
\hline 3 & $V_{L}=\frac{(1-T) E\left(X_{t+1}\right)}{K_{L}^{*}}$ \\
\hline 4 & $K_{L, t}^{*}=K_{U}^{*}\left(1-T \frac{D_{t}^{*}}{V_{t}^{*}}\right)$ \\
\hline 5 & $S_{t}=\frac{(1-T) E\left(X_{t+1}-K_{D} D_{t}\right)}{K_{E}^{*}}$ \\
\hline 6 & $K_{E, t}^{*}=K_{U}^{*}+\frac{D_{t}^{*}}{S_{t}}(1-T)\left(K_{U}^{*}-K_{D}^{*}\right)$ \\
\hline
\end{tabular}

This table summarizes the unified formulas for both growth and no-growth firms. The unified formulas use a set of new symbols:

\section{PUZZLES AND ANSWERS}

With the results in the previous sections, we piece together the unsolved puzzles in the Introduction. The source of puzzlement is the inconsistent use of the outstanding debt on balance sheet. If we use the outstanding debt $D$ and accept that the future tax savings increase for a growth firm, then they have equation (15):

$V_{L, 0}^{\prime}=S_{0}+D=V_{U, 0}+T \frac{K_{D} D}{K_{D}-g}=V_{U, t}+V T S$

where VTS is the value of tax shields for a growth firm. It is easy to see that the VTS can be greater than the outstanding debt $D$ :

$V T S_{t}=\frac{T K_{D} D}{K_{D}-g}>D$

if

$$
g>K_{D}(1-T)
$$

This condition can be satisfied for high growth firms. This nonsensical result comes from an apple to orange comparison. The underlying assumption of VTS is growing future interest payments, while the outstanding debt $D$ has constant interest payments. In (17) apple is compared to orange.

If the debt is also based on the future increasing interest payments, then $V T S_{t}=T D_{t}^{*}$ and the value of tax shields is strictly less than the debt implied by future interest payments $D_{t}^{*}$

$V T S_{t}=T D_{t}^{*}<D_{t}^{*}$ 
In words, for a firm with a high growth rate, it is possible that the firm's VTS can be greater than its outstanding debt, but the VTS can never be greater than the implied debt.

In (16) the value of levered equity can be greater than the value of unlevered equity:

$$
S_{t}^{\prime}=V_{U, t}+V T S_{t}-D>V_{U, t}
$$

if $V T S_{t}>D$ (17). The equity value $S_{t}^{\prime}$ is based on the outstanding debt. If the implied debt is used the value of levered equity is strictly less than the value of unlevered equity

$S_{t}=V_{U, t}+T D_{t}^{*}-D_{t}^{*}<V_{U, t}$

The above two examples illustrate how the confusion of debt leads to the puzzles. Replacing the outstanding debt with the implied debt we have an internally consistent theory of growth firms. In the following section, Discussions, we comment on the consistency of extending the M\&M theory to growth firms.

\section{DISCUSSIONS}

In their theory of capital structure M\&M make a number of assumptions explicitly or implicitly:

1. A portfolio is constructed using the market securities.

2. The market value of a security is the present value of the expected future cash flows. For example, the debt value is the present value of future interest and principle payments.

3. The leverage of a firm is constant.

The above three assumptions are satisfied for no growth firms. However not all three are satisfied for growth firms. If Assumptions 1 and 2 are satisfied, then Assumption 3 is violated.

1. A portfolio is constructed using the market securities.

2. The equity value reflects investors' expectations of future growing cash flows of the firm, while the firm's outstanding debt is the present value of the future constant interest payments of the firm.

3. Consequently, the firm leverage would not be constant.

The firm has an equity expected to grow while the firm has "a permanent level of debt". The leverage of a growth firm will decrease with time. One may adopt decreasing leverage in Assumption 3, and derive different results for such growth firms.

To keep the assumption of constant leverage, we can modify Assumptions 1 and 2:

1. A portfolio is constructed using the market equities and the implied debt.

2. The equity value reflects investors' expectations of future growing cash flows to shareholders, and the implied debt is the present value of the future growing interest payments paid by the firm.

3. The leverage of the firm is constant.

We have shown that, by introducing the implied debt $D^{*}$, the M\&M formulas hold for growth firms. In fact, the common estimate of WACC of a growth firm assumes a constant leverage ratio. Therefore, when the WACC is used in capital budgeting or asset valuation, the implied debt is assumed implicitly. One may modify M\&M's Assumptions 1-3 in different ways and construct different models of growth firms. However, for a consistent theory Assumptions 1-3 must go hand-in-hand. Besides the theoretical reason for the introduction of the implied debt, an empirical support is the observation that growth firms increase their debt over time. Particularly, high growth firms have less debt on their balance sheets than no-growth or low-growth firms. If the implied debt is used in leverage estimations, the leverage of growth firms would be adjusted higher. The greater the growth rate, the larger the adjustment. This may partially explain why the high-growth firms have small amount of outstanding debt on their balance sheets.

It is generally accepted that investors take a firm's future earning growth into account when valuing the firm's equity. Nonetheless, same thing can not be said for a firm's debt. One may argue that there is 
no bonds (implied debt) with growing interest payments on the market. All firms strive for equity growth, while a firm's debt level in the future is the firm's choice. Is it far-fetched to claim that investors take into account a firm's future growing interest payments when estimating the firm's leverage? This is an empirical question and the answer has an important bearing on issues ranging from estimates of VTS, WACC, the values of growth firms, to the theory of capital structure in general.

\section{ENDNOTES}

1. We are grateful to Ian Cooper for his comments, Michael Calegari for many valuable and helpful suggestions at the AAA Conference, and Debra Sounders for elucidating the tax code for bond.

2. William L. Safire, Sleeper Spy (1995).

3. We adopt the APV approach because, as shown by Miles and Ezzell (1980), it is a more general approach. For instance, the weighted average cost of capital (WACC) is a special case of the APV approach.

4. The beta of the levered firm can be expressed as a weighted average of the beta of the unlevered firm and the beta of debt:

$$
\beta_{L}=\frac{V_{U}}{V_{L}} \beta_{U}+\frac{T D}{V_{L}} \beta_{D}
$$

where $\beta_{L}$ and $\beta_{U}$ are the betas of the levered and the unlevered firms, and $\beta_{D}$ is the beta of debt.

\section{REFERENCES}

Brealey, R. A., \& Myers, S. C. (2007). Principles of Corporate Finance. McGraw-Hill, New York.

Brigham, E. F., \& Daves, P. R. (2007). Intermediate Financial Management. Thomson/South-Western, Mason, Ohio.

Cooper, I. A., \& Nyborg, K. G. (2006). The value of tax shields is equal to the present value of tax shields. Journal of Financial Economics, newblock Journal of Financial Economics, 81, 215-225.

Fernandez, P. (2004). The value of tax shields is not equal to the present value of tax shields. Journal of Financial Economics, 73, 145-165.

Fernandez, P. (2007). A more realistic valuation: APV and WACC with constant book leverage ratio. Journal of Applied Finance, 17(2), 13-20.

Harris, R. S., \& Pringle, J. J. (1985). Risk-adjusted discount rates: Extensions from the average risk case. Journal of Financial Research, 8, 237-244.

Liu, Y-C. (2009). The slicing approach to valuing tax shields. Journal of Banking \& Finance, 33(6), 1069 $-1078$.

Mayer, D. (1973). Nonmarketable assets and the determination of capital asset prices in the absence of a riskless asset. Journal of Business, 46, 258-267.

Miles, J., \& Ezzell, J. R. (1980). The weighted average cost of capital, perfect capital markets, and project life: A clarification. Journal of Financial and Quantitative Analysis, 15, 719-730.

Modigliani, F., \& Miller, M. H. (1958). The cost of capital, corporate finance, and the theory of investment. American Economic Review, 48, 261-297.

Modigliani, F., \& Miller, M. H. (1963). Corporate income taxes and the cost of capital: a correction. American Economic Review, 53, 433-443.

Ruback, R. (2002).Capital cash flows: A simple approach to valuing risky cash flows. Financial Management, 31, 85-103. 